\title{
Synthesis and Structure of a Polymeric Homobimetallic Mercury Compound Constructed from $(E)$-Acetyloxy\{4-[(pyridin-2- ylmethylene)amino]phenyl\}mercury(II)
}

\author{
Tushar S. Basu Baul ${ }^{1}$ - Imliwati Longkumer ${ }^{1} \cdot$ Anthony Linden $^{2}$
}

Received: 1 December 2014/Accepted: 19 August 2015/Published online: 29 August 2015

(C) Springer Science+Business Media New York 2015

\begin{abstract}
A two-dimensional homobimetallic mercury coordination polymer (2-\{[4-(acetyloxymercuryl)phenyl]imi nomethyl $\}$ pyridine- $\left.\kappa^{2} \mathrm{~N}, \mathrm{~N}^{\prime}\right)$ dithiocyanatomercury(II) (1) was synthesized and characterized by FT-IR, ${ }^{1} \mathrm{H}-\mathrm{NMR}$ spectroscopic and single crystal X-ray diffraction techniques. Crystallographic results reveal that the primary structural building unit in the structure is a centrosymmetric tetranuclear entity,
\end{abstract}

where long $\mathrm{Hg}-\mathrm{N}$ bonds link a thiocyanate ligand of the dinuclear asymmetric unit to the acetate coordinated $\mathrm{Hg}$-atom of its neighbor. These tetranuclear units are then linked into extended chains and the chains are cross-linked by weaker $\mathrm{Hg}$... $\mathrm{O}$ interactions to give a two-dimensional polymeric structure.

Graphical Abstract Part of the structure of the 2-D

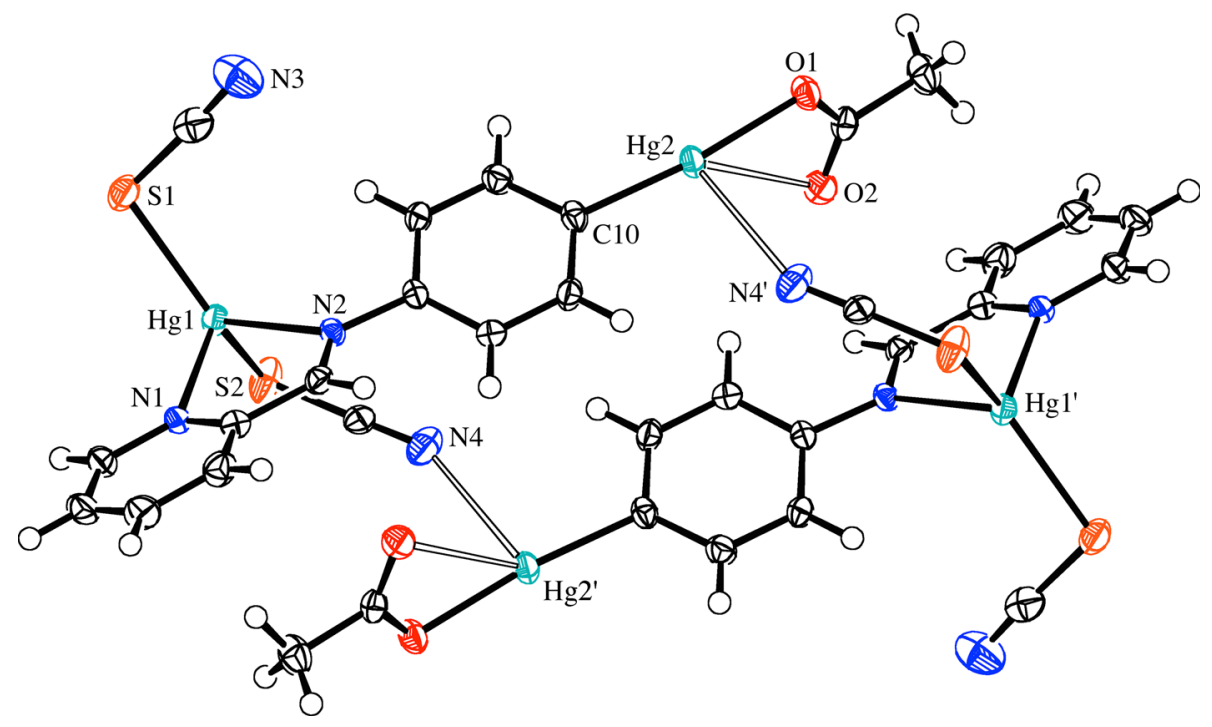

Tushar S. Basu Baul

basubaulchem@gmail.com; basubaul@nehu.ac.in

$\triangle$ Anthony Linden

anthony.linden@chem.uzh.ch

1 Centre for Advanced Studies in Chemistry, North-Eastern Hill University, NEHU Permanent Campus, Umshing, Shillong 793 022, India

2 Department of Chemistry, University of Zurich, Winterthurerstrasse 190, 8057 Zurich, Switzerland bimetallic mercury coordination polymer constructed from the reaction of $(E)$-acetyloxy\{4-[(pyridin-2-ylmethylene) amino]phenyl $\}$ mercury(II) with $\mathrm{Hg}(\mathrm{SCN})_{2}$ is reported.

Keywords Single-crystal X-ray diffraction - Structural building unit · Organomercury · Homobimetallic . $N, N^{\prime}$-donor · Organomercurio-ligand 


\section{Introduction}

The coordination chemistry of mercury has received considerable attention, in part due to concerns regarding the impact on the environment and on health [1,2]. Complexes of mercury(II) have been used for the detection of heavy metals and also for their removal. On the other hand, the coordination and structural chemistry of mercury is also well investigated: mercury(II) with a large ionic radius as a consequence of the filled $4 f$ and $3 d$ electron shells, displays highly varied coordination numbers and flexible and often distorted coordination geometries, although tetrahedral geometry appears frequently. Consequently, mercury can readily accommodate all kinds of architectures in coordination polymers, including $1 \mathrm{D}, 2 \mathrm{D}$ and $3 \mathrm{D}$ topologies [3, 4], with $1 \mathrm{D}$ coordination polymers occurring more frequently than 3D polymers [4]. Moreover, the effects related to the geometry, size, number of donor atoms and rigidity of ligands, as well as the number and size of anions, are important contributors to the greater number of one-dimensional coordination polymers [4].

In this perspective, mercury complexes of Schiff-base ligands, such as $(E)$ - $N$-(pyridin-2-ylmethylene)arylamine, have received attention owing to their distinctive coordination and structural properties [5-7]. Recent X-ray crystallographic studies performed on a variety of such mercury(II) compounds, viz. $\left[\mathrm{HgL}(\mathrm{X})_{2}\right],\left[\mathrm{HgL}(\mathrm{X})_{2}(\mathrm{~S})\right]$, $\left[\mathrm{HgL}(\mathrm{X})_{2}\right]_{2},\left[\mathrm{HgL}(\mathrm{X})_{2}\right]_{\mathrm{n}},\left\{\left[\mathrm{HgL}(\mathrm{X})_{2}\right]_{2}\right\}_{\mathrm{n}}$ and $\left\{\left[\mathrm{HgL}(\mathrm{X})_{2}\right]_{2}\right.$ $\left.\cdot \operatorname{Hg}(\mathrm{X})_{2}\right\}_{\mathrm{n}}(\mathrm{X}=$ halides, azides or nitrates and $\mathrm{S}=$ coordinating solvent; Scheme 1), revealed that these complexes are promising for the generation of interesting and diverse supramolecular assemblies. These assemblies are produced through the formation of coordination bonds, hydrogen bonds and other intermolecular interactions, thereby creating a large variety of supramolecular architectures [5-7]. Although the global topology (monomer, dimer, polymer, etc.) of the resulting compound is determined by the interplay between $\mathrm{Hg}^{2+}, \mathrm{X}^{-}$, and $\mathrm{L}$, in the solid-state, the crystal structure is frequently controlled by weaker intermolecular interactions such as $\pi-\pi$ and $\mathrm{CH}-\pi$ contacts [57]. We have recently described the isolation and characterization of an organomercurio-ligand: $2-\{[$ (4-chloromercuryl)phenyl]iminomethyl $\}$ pyridine (L) which was used for the construction of bimetallic mercuric chloride compounds, (2-\{[4-(chloromercuryl)phenyl]iminomethyl $\}$ pyrid ine- $\kappa^{2} N, N^{\prime}$ )dichloromercury(II) (dimethylsulfoxide- $\kappa \mathrm{O}$ ) ( $\left.\mathrm{LHgCl}_{2} \cdot \mathrm{DMSO}\right)$ and (2-\{[4-(chloromercuryl)phenyl]iminomethyl pyridine- $\kappa^{2} N, N^{\prime}$ )dichloromercury(II) (dimethylformamide- $\kappa O)$ ( $\left.\mathrm{LHgCl}_{2} \cdot \mathrm{DMF}\right)$, and cadmium chloride compound, (2-\{[4-(chloromercuryl)phenyl]iminomethyl $\}$ pyridine- $\kappa^{2} N, N^{\prime}$ )dichlorocadmium(II) (dimethylformami de- $\kappa O)\left(\mathrm{LCdCl}_{2} \cdot \mathrm{DMF}\right)$ [8]. As a part of an on-going investigation into the synthesis and structures of bimetallic mercury compounds, we now report the reaction of $(E)$ acetyloxy $\{4-[($ pyridin-2-ylmethylene $)$ amino $]$ phenyl $\}$ mercu ry(II) [8] with $\mathrm{Hg}(\mathrm{SCN})_{2}$, which provided a polymeric homobimetallic compound (2-\{[4-(acetyloxymercuryl)ph enyl]iminomethyl $\}$ pyridine $-\kappa^{2} N, N^{\prime}$ ) dithiocyanatomercury (II) (1) (Scheme 2). The structure of $\mathbf{1}$ has been elucidated from spectroscopic and X-ray diffraction results.

\section{Experimental}

\section{Materials}

Caution! Compounds of mercury are highly toxic [9]. Care must be taken when handling samples, and appropriate disposal procedures are necessary. All chemicals were used as purchased without purification: pyridine-2-carbaldehyde (Merck), mercuric acetate (Loba chemicals), mercuric thiocyanate (Loba Chemie), except for aniline (Sd Fine), which was freshly distilled prior to use. Solvents were purified by standard procedures and were freshly distilled prior to use.

\section{Physical Measurements}

Melting points were recorded in capillary tubes on a Scanca apparatus and are uncorrected. Elemental analyses were performed using a Perkin Elmer 2400 series II instrument. IR spectra in the range $4000-400 \mathrm{~cm}^{-1}$ were obtained on a Perkin Elmer Spectrum BX series FT-IR spectrophotometer with samples investigated as $\mathrm{KBr}$ discs. The ${ }^{1} \mathrm{H}$ NMR spectra were recorded on a Bruker Avance II spectrometer and measured at $400.13 \mathrm{MHz}$. The ${ }^{1} \mathrm{H}$ chemical shifts were referenced to $\mathrm{Me}_{4} \mathrm{Si}$ set at $0.00 \mathrm{ppm}$.

\section{Synthesis of (E)-Acetyloxy \{4-[(pyridin-2- ylmethylene)amino]phenyl\}mercury(II)}

The compound was prepared by reacting pyridine-2-carbaldehyde and acetyloxy(4-aminophenyl)mercury(II) in ethanol under reflux conditions [8]. The spectroscopic data of the compound reported in Ref. [8] correspond well within the experimental errors with those of this freshly prepared sample.

\section{Synthesis of (2-\{[4-(Acetyloxymercuryl)phenyl] iminomethyl $\}$ pyridine- $\left.\kappa^{2} \mathrm{~N}, \mathrm{~N}^{\prime}\right)$ dithiocyanato mercury(II) (1)}

To a hot Solution of (E)-acetyloxy\{4-[(pyridin-2-ylmethylene)amino]phenyl $\}$ mercury(II) $(0.50 \mathrm{~g}, 1.13 \mathrm{mmol})$ in methanol $(15 \mathrm{ml})$ was added a solution of $\mathrm{Hg}(\mathrm{SCN})_{2}$ 
Scheme 1 Schematic representation of various structural motifs (I-VI) observed in mercury(II) compounds with $(E)-N$-(pyridin2-ylmethylidene)arylamine

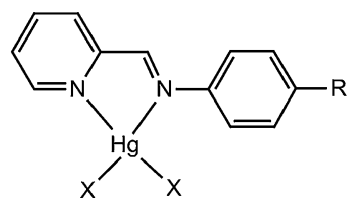

$\mathrm{R}=\mathrm{H}, \mathrm{X}=\mathrm{I} ; \mathrm{R}=\mathrm{CH}_{3}, \mathrm{X}=\mathrm{I} ; \mathrm{R}=$ $\mathrm{CO}_{2} \mathrm{CH}_{3}, \mathrm{X}=\mathrm{Br} ; \mathrm{R}=\mathrm{CO}_{2} \mathrm{CH}_{3}, \mathrm{X}=\mathrm{I}$

$\left[\mathrm{HgL}(\mathrm{X})_{2}\right]$ : la

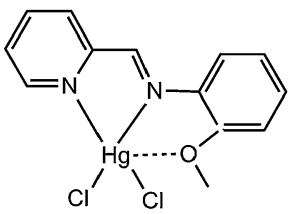

$\left[\mathrm{HgL}(\mathrm{X})_{2}\right]: \mathbf{l b}$

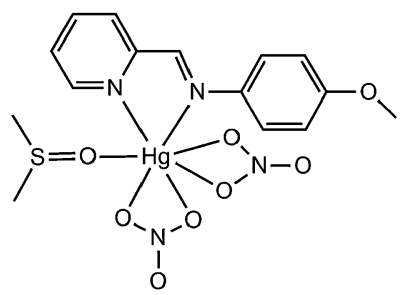

$\left[\mathrm{HgL}(\mathrm{X})_{2}(\mathrm{~S})\right]$ : II

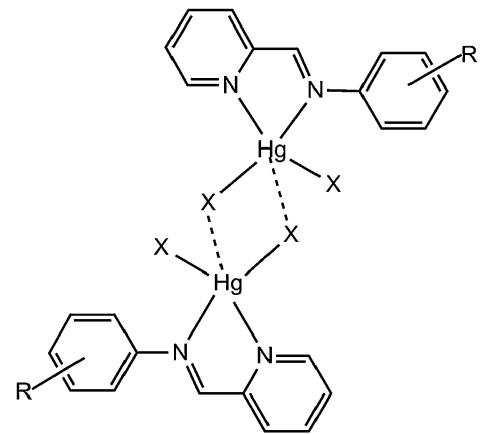

$\mathrm{R}=\mathrm{H}, \mathrm{X}=\mathrm{Cl} ; \mathrm{R}=\mathrm{H}, \mathrm{X}=\mathrm{Br} ; \mathrm{R}=2-\mathrm{CH}_{3}, \mathrm{X}=$ $\mathrm{Cl} ; \mathrm{R}=3-\mathrm{CH}_{3}, \mathrm{X}=\mathrm{Cl} ; \mathrm{R}=4-\mathrm{CH}_{3}, \mathrm{X}=\mathrm{Cl} ; \mathrm{R}=$ $4-\mathrm{CH}_{3}, \mathrm{X}=\mathrm{Br} ; \mathrm{R}=4-\mathrm{CH}_{2} \mathrm{CH}_{3}, \mathrm{X}=\mathrm{Cl} ; \mathrm{R}=4$ $\mathrm{OCH}_{2} \mathrm{CH}_{3}, \mathrm{X}=\mathrm{Cl} ; \mathrm{R}=4-\mathrm{Cl}, \mathrm{X}=\mathrm{Cl} ; \mathrm{R}=4$ -

$\mathrm{CO}_{2} \mathrm{CH}_{3}, \mathrm{X}=\mathrm{Cl} ; \mathrm{R}=4-\mathrm{CO}_{2} \mathrm{CH}_{3}, \mathrm{X}=\mathrm{Br}$

$\left[\mathrm{HgL}(\mathrm{X})_{2}\right]_{2}$ : IIla

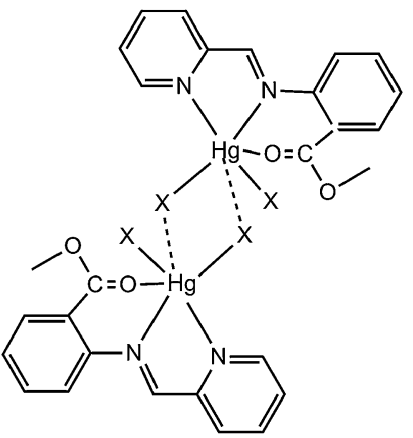

$\mathrm{R}=2-\mathrm{CO}_{2} \mathrm{CH}_{3}, \mathrm{X}=\mathrm{Cl}$

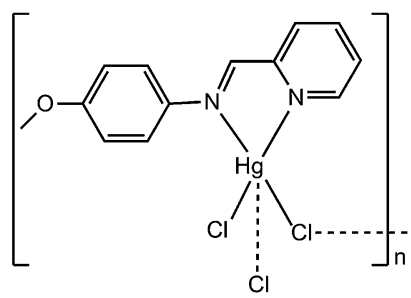

$\left[\mathrm{HgL}(\mathrm{X})_{2}\right]_{n}:$ IVa

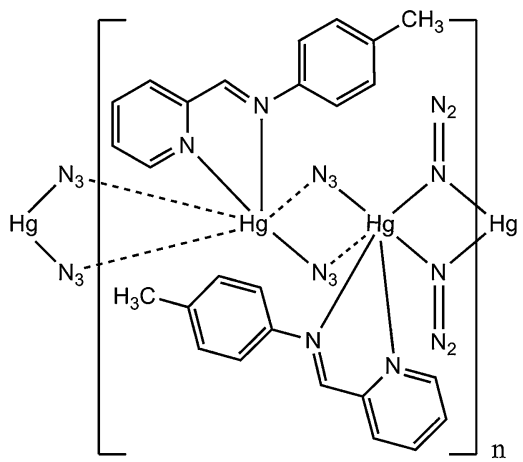

$\left\{\left[\operatorname{HgL}(\mathrm{X})_{2}\right]_{2}\right\}_{n}: \mathbf{V}$

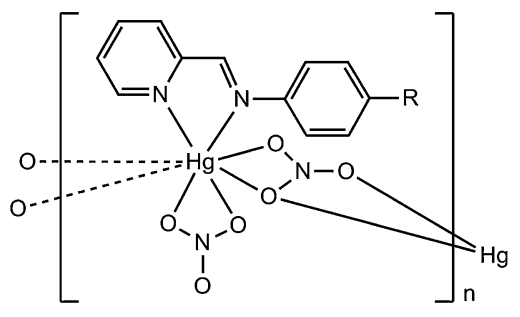

$\left(\mathrm{R}=\mathrm{CH}_{3}\right.$ or $\mathrm{OCH}_{3}$ )

$\left[\mathrm{HgL}(\mathrm{X})_{2}\right]_{n}: \mathbf{I V b}$

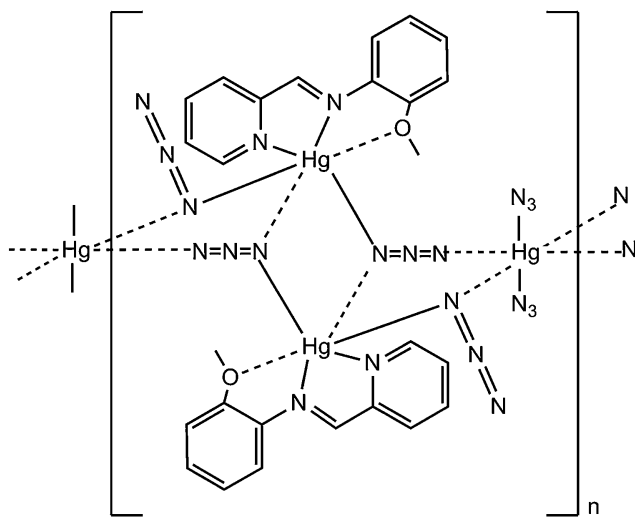

$\left\{\left[\mathrm{HgL}(\mathrm{X})_{2}\right]_{2} \cdot \mathrm{Hg}(\mathrm{X})_{2}\right\}_{n}: \mathrm{V} \mathbf{I}$ 
Scheme 2 Reaction showing the synthesis of polymeric homobimetallic mercury thiocyanato compound 1

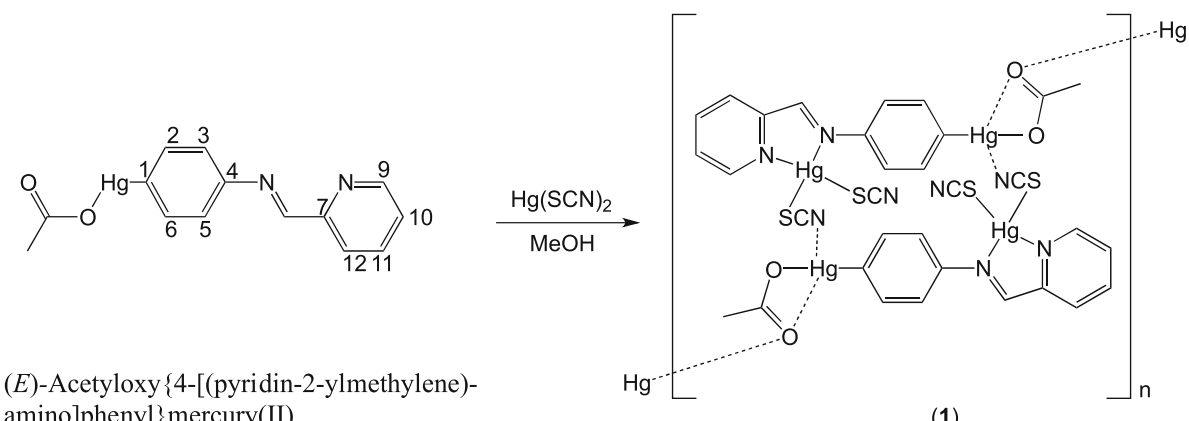

(1)
$(0.36 \mathrm{~g}, 1.13 \mathrm{mmol})$ in methanol $(20 \mathrm{ml})$ under stirring conditions which resulted in the immediate formation of a pale yellow precipitate. The stirring was continued for $4 \mathrm{~h}$. The precipitate was filtered and washed with methanol $(3 \times 5 \mathrm{ml})$ and dried in vacuo. The product was insoluble in common organic solvents. Yield: $78 \%$ (0.67 g). M.p.: 431-433 K (dec.). Anal. Found: C, 25.50; H, 1.75; N, $7.60 \%$. Calc. for $\mathrm{C}_{16} \mathrm{H}_{12} \mathrm{Hg}_{2} \mathrm{~N}_{4} \mathrm{O}_{2} \mathrm{~S}_{2}: \mathrm{C}, 25.37 ; \mathrm{H}, 1.60 ; \mathrm{N}$, $7.40 \%$. IR ( $\left.\mathrm{KBr} \mathrm{cm}{ }^{-1}\right): 2139,2108 v_{\text {as }}(\mathrm{CN}(\mathrm{Hg}-\mathrm{SCN}))$, $1627 v_{\text {as }}(\mathrm{OCO}), 1586 v_{\text {as }}(\mathrm{C}(\mathrm{H})=\mathrm{N}), 1483,1440 v(\mathrm{C}=\mathrm{N})$ py. ${ }^{1} \mathrm{H}$ NMR (DMSO- $\left.d_{6}\right): 9.05$ [s, $\left.1 \mathrm{H}, \mathrm{CH}=\mathrm{N}\right], 8.89$ [d, $\mathrm{J}=5.0 \mathrm{~Hz}, 1 \mathrm{H}, \mathrm{H}-9], 8.13[\mathrm{t}, 1 \mathrm{H}, \mathrm{H}-11], 8.04$ [d, $\mathrm{J}=7.0 \mathrm{~Hz}, 1 \mathrm{H}, \mathrm{H}-12], 7.76$ [t, 1H, H-10], 7.51 [d, 4H, $\mathrm{H}-2,6,3,5], 1.98\left[\mathrm{~s}, 3 \mathrm{H}, \mathrm{CH}_{3} \mathrm{CO}_{2}\right] \mathrm{ppm}$.

\section{Crystal Structure Determination}

Crystals of compound $\mathbf{1}$ suitable for an X-ray crystalstructure determination were obtained from the slow evaporation of an acetonitrile/DMF solution $(1: 1)$ of the compound at room temperature. The measurement was made at low temperature on an Agilent Technologies Super Nova area-detector diffractometer [10] using Mo $\mathrm{K} \alpha$ radiation $(\lambda=0.71073 \AA)$ from a micro-focus X-ray source and an Oxford Instruments Cryojet XL cooler. Data reduction was performed with CrysAlisPro [10]. The intensities were corrected for Lorentz and polarization effects, and a numerical absorption correction [11] was applied. Equivalent reflections were merged. The data collection and refinement parameters are given in Table 1. The structure was solved by direct methods using SHELXS97 [12], which revealed the positions of all nonhydrogen atoms. The non-hydrogen atoms were refined anisotropically. All H-atoms were placed in geometrically calculated positions and refined by using a riding model where each $\mathrm{H}$-atom was assigned a fixed isotropic displacement parameter with a value equal to $1.2 U_{\text {eq }}$ of its parent $\mathrm{C}$-atom $\left(1.5 U_{\mathrm{eq}}\right.$ for the methyl group). The refinement of the structure was carried out on $F^{2}$ by using fullmatrix least-squares procedures, which minimized the function $\sum w\left(F_{\mathrm{o}}^{2}-F_{\mathrm{c}}^{2}\right)^{2}$. A correction for secondary
Table 1 Crystallographic data and structure refinement parameter for

\begin{tabular}{|c|c|}
\hline Empirical formula & $\mathrm{C}_{32} \mathrm{H}_{24} \mathrm{Hg}_{4} \mathrm{~N}_{8} \mathrm{O}_{4} \mathrm{~S}_{4}$ \\
\hline Formula weight & 1515.19 \\
\hline Crystal size (mm) & $0.05 \times 0.14 \times 0.20$ \\
\hline Crystal color, habit & Red, tablet \\
\hline Temperature (K) & $160(1)$ \\
\hline Crystal system & Monoclinic \\
\hline Space group & $P 2_{1} / c$ \\
\hline$a(\AA)$ & $14.8405(2)$ \\
\hline$b(\AA)$ & $8.20466(10)$ \\
\hline$c(\AA)$ & $15.8137(2)$ \\
\hline$\beta\left(^{\circ}\right)$ & $105.4188(15)$ \\
\hline$V\left(\AA^{3}\right)$ & $1856.19(4)$ \\
\hline$Z$ & 2 \\
\hline$D_{x}\left(\mathrm{~g} \mathrm{~cm}^{-3}\right)$ & 2.711 \\
\hline$\mu\left(\mathrm{mm}^{-1}\right)$ & 16.765 \\
\hline Transmission factors (min, max) & $0.081 ; 0.428$ \\
\hline$\theta$ range for data collection $\left(^{\circ}\right)$ & $2.6-29.0$ \\
\hline Reflections measured & 19,943 \\
\hline Independent reflections $\left(R_{\mathrm{int}}\right)$ & $4416(0.028)$ \\
\hline Reflections with $I>2 \sigma(I)$ & 4049 \\
\hline Number of parameters & 236 \\
\hline$R(F)(I>2 \sigma(I)$ reflns $)$ & 0.0213 \\
\hline$w R\left(F^{2}\right)$ (all data) & 0.0492 \\
\hline$G O F\left(F^{2}\right)$ & 1.066 \\
\hline $\operatorname{Max}, \min \Delta \rho\left(\mathrm{e} / \AA^{3}\right)$ & $3.07 ;-1.10$ \\
\hline
\end{tabular}

extinction was not applied. The SHELXL2013 program [13] was used for all calculations.

\section{Results and Discussion}

\section{Synthetic and Spectroscopic Aspects}

Recently, we have reported the synthesis and structures of the bimetallic compounds $\mathrm{LHgCl}_{2} \cdot \mathrm{DMSO}, \mathrm{LHgCl}_{2} \cdot \mathrm{DMF}$ 
Fig. 1 The structure of the tetranuclear SBU of $\mathbf{1}(50 \%$ probability ellipsoids for the non-H atoms). The asymmetric unit is half of this. The symmetry operators for the primed atoms are as defined in Table 2

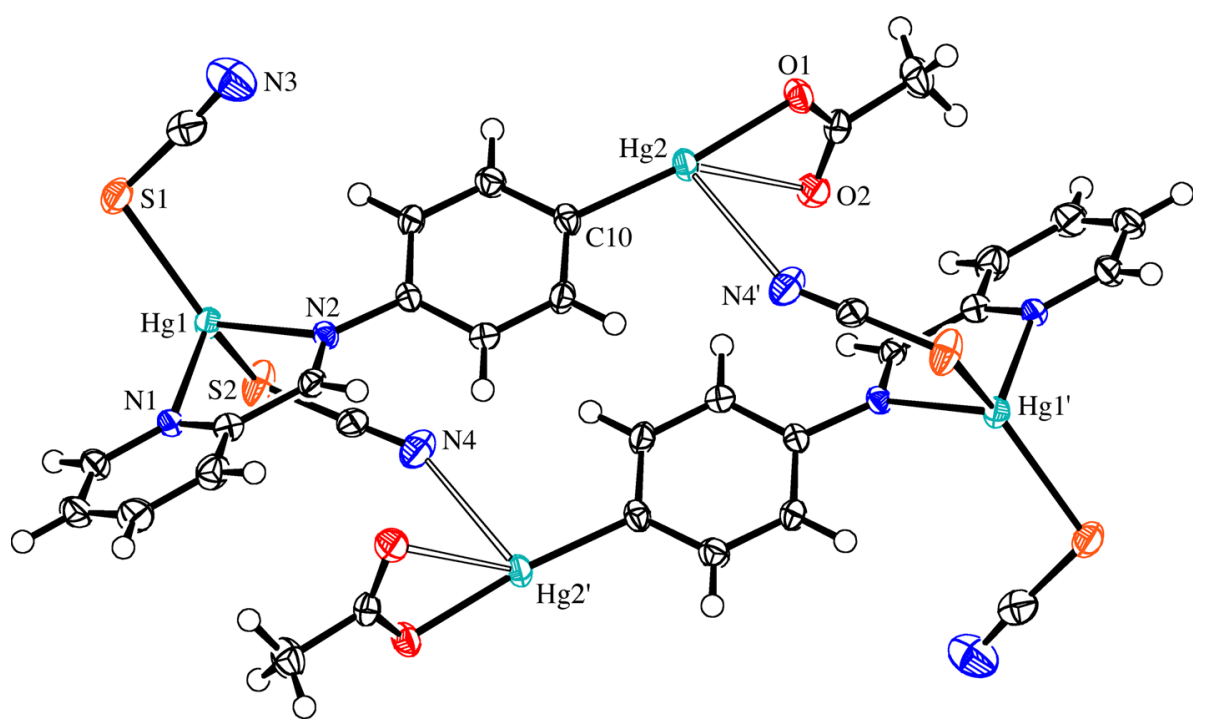

and $\mathrm{LCdCl}_{2} \cdot \mathrm{DMF}$, which were synthesized from the metallo-ligand precursor $2-\{[(4-$ chloromercuryl $)$ phenyl $]$ iminomethyl $\}$ pyridine (L) [8]. In another endeavor, a metalloligand (E)-acetyloxy \{4-[(pyridin-2-ylmethylene)amino] phenyl $\}$ mercury(II) was prepared by reacting acetyloxy(4aminophenyl)mercury with pyridine-2-carbaldehyde in absolute ethanol according to the usual condensation reaction [8]. The metallo-ligand of the present investigation also contains imino- and pyridyl nitrogen atoms, which are capable of coordinating to additional metal atom. In view of this, reaction of the metallo-ligand with $\mathrm{Hg}(\mathrm{SCN})_{2}$ was attempted in order to obtain a bimetallic derivative. The compound (2-\{[4-(acetyloxymercuryl)phenyl]iminomethyl $\}$ pyridine- $\kappa^{2} N, N^{\prime}$ )dithiocyanatomercury(II) (Scheme 2) has been isolated and characterized using IR and ${ }^{1} \mathrm{H}$ NMR spectroscopy. The ${ }^{1} \mathrm{H}$ NMR spectrum of $\mathbf{1}$ revealed the presence of the metallo-ligand skeleton. In the IR spectrum of $\mathbf{1}$, the $v_{\mathrm{as}}(\mathrm{CN})$ stretch of the thiocyanate ligand appears at 2139 and $2108 \mathrm{~cm}^{-1}$. This indicates S-coordination of the bound thiocyanate to the mercury atom $[14,15]$. This hypothesis regarding the coordination behavior of the ambidentate pseudohalide is corroborated further by the single crystal X-ray crystallography.

\section{Crystal Structure}

Complex $\mathbf{1}$ is a two-dimensional coordination polymer. The asymmetric unit contains two chemically and structurally distinct $\mathrm{Hg}$-atoms, two thiocyanate ligands, one acetate ligand and one imine ligand, L (Fig. 1). Within the asymmetric unit, atom $\mathrm{Hg}(1)$ is coordinated in a distorted tetrahedral fashion by the S-atoms of two thiocyanate ligands, and the two $\mathrm{N}$-atoms of $\mathrm{L}$ acting in a bidentate chelating mode (Table 2). The small bite angle of $71.89(11)^{\circ}$ of the chelating $\mathrm{N}$-atoms contrasts with the large angle of $129.56(4)^{\circ}$ subtended by the two thiocyanate $\mathrm{S}$-atoms at $\mathrm{Hg}(1)$. The primary coordination sphere of atom $\mathrm{Hg}(2)$ contains the carboxy O-atom, $\mathrm{O}(1)$, of the acetate ligand and the para-positioned $\mathrm{C}$-atom of the phenyl ring of $\mathrm{L}$ disposed in an almost linear arrangement with the angle at $\mathrm{Hg}(2)$ being $173.82(14)^{\circ}$. However, atom $\mathrm{Hg}(2)$ is involved in three additional longer, but still significant interactions (Table 2), given that the sums of the van der Waals radii of $\mathrm{Hg}$ and $\mathrm{N}$, and $\mathrm{Hg}$ and $\mathrm{O}$ are approximately $3.3 \AA$ [8]. The carbonyl O-atom, $\mathrm{O}(2)$, of the acetate ligand is $2.848(3) \AA$ from $\mathrm{Hg}(2)$, thereby completing an asymmetric bidentate chelation of this ligand to $\operatorname{Hg}(2)$, while $\mathrm{O}(2)$ from another asymmetric unit, $\mathrm{O}\left(2^{\prime \prime}\right)$, is involved in a long $\mathrm{Hg} \cdots \mathrm{O}$ interaction of $2.888(3) \AA$ to atom $\mathrm{Hg}(2)$; atom $\mathrm{O}(2)$ thus weakly bridges two $\mathrm{Hg}(2)$ atoms. The fifth interaction with $\mathrm{Hg}(2)$ is a long $\mathrm{Hg}(2)-\mathrm{N}\left(4^{\prime}\right)$ bond of 2.726(4) $\AA$ involving a thiocyanate $\mathrm{N}$-atom from a third asymmetric unit. The overall coordination geometry at $\mathrm{Hg}$ (2) cannot easily be described by any classical shape, but is perhaps most closely associated with a distorted square pyramid where atom $\mathrm{N}\left(4^{\prime}\right)$ is at the apex. A similar asymmetric geometry for a bidentate acetate ligand and long linking $\mathrm{Hg}-\mathrm{N}$ distance were observed in the polymeric chain structure of acetyloxy(4-aminophenyl)mercury(II) [8].

The primary structural building unit (SBU) in the structure can be considered to be a centrosymmetric tetranuclear entity, where the $\operatorname{Hg}(2)-\mathrm{N}\left(4^{\prime}\right)$ bond links a thiocyanate ligand of the dinuclear asymmetric unit to the acetate-coordinated $\mathrm{Hg}$-atom, $\mathrm{Hg}(2)$, of its centrosymmetrically-related neighbor and vice versa (Fig. 1). These SBUs are then linked into extended chains running parallel to the [010] direction by the weak $\mathrm{Hg}(2) \cdots \mathrm{O}\left(2^{\prime \prime}\right)$ type 
Table 2 Selected bond lengths (A) and angles $\left({ }^{\circ}\right)$ in the structures of compound $\mathbf{1}$ and the related bimetallic compounds $\mathrm{LHgCl}_{2} \cdot \mathrm{DMSO}$, $\mathrm{LHgCl}_{2} \cdot \mathrm{DMF}$ and $\mathrm{LCdCl}_{2} \cdot \mathrm{DMF}$

\begin{tabular}{|c|c|c|c|c|}
\hline & 1 & $\mathrm{LHgCl}_{2} \cdot \mathrm{DMSO}$ & $\mathrm{LHgCl}_{2} \cdot \mathrm{DMF}$ & $\mathrm{LCdCl}_{2} \cdot \mathrm{DMF}$ \\
\hline $\mathrm{M}(1)-\mathrm{N}(1)$ & $2.363(3)$ & $2.310(4)$ & $2.296(3)$ & $2.319(2)$ \\
\hline $\mathrm{M}(1)-\mathrm{N}(2)$ & $2.353(3)$ & $2.464(4)$ & $2.505(3)$ & $2.417(2)$ \\
\hline $\mathrm{M}(1)-\mathrm{X}(1)$ & $2.4624(12)$ & $2.4679(14)$ & $2.4283(8)$ & $2.4426(6)$ \\
\hline$M(1)-X(2)$ & $2.4433(11)$ & $2.4172(14)$ & $2.4629(8)$ & $2.4544(7)$ \\
\hline $\mathrm{Hg}(2)-\mathrm{C}(10)$ & $2.046(4)$ & $2.057(5)$ & $2.062(3)$ & $2.057(3)$ \\
\hline $\mathrm{Hg}(2)-\mathrm{O}(1)$ & $2.085(3)$ & - & - & - \\
\hline $\mathrm{Hg}(2) \cdots \mathrm{O}(2)$ & $2.848(3)$ & - & - & - \\
\hline $\mathrm{Hg}(2)-\mathrm{N}\left(4^{\prime}\right)$ & $2.762(4)$ & - & - & - \\
\hline $\mathrm{Hg}(2) \cdots \mathrm{O}\left(2^{\prime \prime}\right)$ & $2.888(3)$ & - & - & - \\
\hline $\mathrm{Hg}(1) \cdots \mathrm{N}\left(3^{*}\right)$ & $3.082(5)$ & - & - & - \\
\hline $\mathrm{N}(1)-\mathrm{M}(1)-\mathrm{X}(1)$ & $105.12(9)$ & $112.42(12)$ & $134.11(7)$ & $132.32(6)$ \\
\hline $\mathrm{N}(1)-\mathrm{M}(1)-\mathrm{X}(2)$ & $116.76(8)$ & $132.92(12)$ & $116.44(7)$ & $117.22(6)$ \\
\hline $\mathrm{N}(2)-\mathrm{M}(1)-\mathrm{X}(1)$ & $113.63(8)$ & $97.77(11)$ & $105.46(6)$ & $104.08(5)$ \\
\hline $\mathrm{N}(2)-\mathrm{M}(1)-\mathrm{X}(2)$ & $105.45(8)$ & $107.24(11)$ & $105.90(6)$ & $101.10(5)$ \\
\hline $\mathrm{N}(1)-\mathrm{M}(1)-\mathrm{N}(2)$ & $71.89(11)$ & $70.82(15)$ & $70.87(9)$ & $71.64(8)$ \\
\hline $\mathrm{X}(1)-\mathrm{M}(1)-\mathrm{X}(2)$ & $129.56(4)$ & $114.37(5)$ & $108.60(3)$ & $110.25(2)$ \\
\hline $\mathrm{N}(2)-\mathrm{Hg}(1) \cdots \mathrm{N}\left(3^{*}\right)$ & $155.18(12)$ & - & - & - \\
\hline $\mathrm{Hg}(1) \cdots \mathrm{N}\left(3^{*}\right)-\mathrm{C}\left(15^{*}\right)$ & $93.3(3)$ & - & - & - \\
\hline $\mathrm{C}(10)-\mathrm{Hg}(2)-\mathrm{O}(1)$ & $173.82(14)$ & - & - & - \\
\hline $\mathrm{C}(10)-\mathrm{Hg}(2) \cdots \mathrm{O}(2)$ & 133.01(12) & - & - & - \\
\hline $\mathrm{C}(10)-\mathrm{Hg}(2) \cdots \mathrm{O}\left(2^{\prime \prime}\right)$ & $99.74(12)$ & - & - & - \\
\hline $\mathrm{C}(10)-\mathrm{Hg}(2)-\mathrm{N}\left(4^{\prime}\right)$ & $98.64(15)$ & - & - & - \\
\hline $\mathrm{O}(1)-\mathrm{Hg}(2) \cdots \mathrm{O}(2)$ & $50.77(10)$ & - & - & - \\
\hline $\mathrm{O}(1)-\mathrm{Hg}(2) \cdots \mathrm{O}\left(2^{\prime \prime}\right)$ & 79.03(10) & - & - & - \\
\hline $\mathrm{O}(1)-\mathrm{Hg}(2)-\mathrm{N}\left(4^{\prime}\right)$ & $86.70(12)$ & - & - & - \\
\hline $\mathrm{O}(2)-\mathrm{Hg}(2) \cdots \mathrm{O}\left(2^{\prime \prime}\right)$ & $123.04(7)$ & - & - & - \\
\hline $\mathrm{O}(2)-\mathrm{Hg}(2)-\mathrm{N}\left(4^{\prime}\right)$ & $80.24(11)$ & - & - & - \\
\hline $\mathrm{N}\left(4^{\prime}\right)-\mathrm{Hg}(2) \cdots \mathrm{O}\left(2^{\prime \prime}\right)$ & $70.70(10)$ & - & - & - \\
\hline $\mathrm{Hg}(2)-\mathrm{O}(2) \cdots \mathrm{O}\left(2^{\prime \prime}\right)$ & $109.63(10)$ & - & - & - \\
\hline
\end{tabular}

$\mathrm{M}=\mathrm{Hg}$ for $\mathrm{LHgCl}_{2} \cdot \mathrm{DMF}, \mathrm{LCdCl}_{2} \cdot \mathrm{DMF}$ and $\mathbf{1}$ and $\mathrm{Cd}$ for $\mathrm{LCdCl}_{2} \cdot \mathrm{DMF} ; \mathrm{X}=\mathrm{Cl}$ for $\mathrm{LHgCl}_{2} \cdot \mathrm{DMSO}$, $\mathrm{LHgCl}_{2} \cdot \mathrm{DMF}$ and $\mathrm{LCdCl}_{2} \cdot \mathrm{DMF}$ and $\mathrm{X}=\mathrm{S}$ for 1

Primed atoms refer to the molecule in the following symmetry related positions for 1 : $^{\prime} 1-x,-y, 1-z$; " $1-x,-\frac{1}{2}+y, \frac{3}{2}-z ; *-x, \frac{1}{2}+y,-\frac{1}{2}-z$

Refer to Ref. [8] for details of compounds $\mathrm{LHgCl}_{2} \cdot \mathrm{DMSO}, \mathrm{LHgCl}_{2} \cdot \mathrm{DMF}$ and $\mathrm{LCdCl}_{2} \cdot \mathrm{DMF}$ interactions. Each SBU is involved at each end in two such chain-forming interactions, with the net result that a twodimensional coordination polymer is formed with the sheets lying parallel to (100) (Fig. 2). The sheets are linked into the overall three-dimensional supramolecular framework by weak $\mathrm{C}-\mathrm{H} \cdots \mathrm{N}$ interactions involving atoms $\mathrm{C}(5)$ and $\mathrm{N}\left(3^{*}\right)$ of adjacent sheets with a $\mathrm{H} \cdots \mathrm{N}$ distance of 2.69 $\AA$ and a $\mathrm{C}-\mathrm{H} \cdots \mathrm{N}$ angle of $137^{\circ}$ (Fig. 3; see Table 2 for the symmetry operator for $\mathrm{N}\left(3^{*}\right)$ ). Across the same gap between the sheets, atom $\mathrm{N}\left(3^{*}\right)$ is only $3.082(5) \AA$ from the opposing atom $\mathrm{Hg}(1)$ and the thiocyanate ligand containing atom $\mathrm{N}\left(3^{*}\right)$ lies partially within the opening at $\mathrm{Hg}(1)$ afforded by the wide $\mathrm{S}(2)-\mathrm{Hg}(1)-\mathrm{S}(2)$ angle. Potentially, this contact could also be contributing to the three- dimensional coherence of the structure, although the $\mathrm{Hg}(1) \cdots \mathrm{N}\left(3^{*}\right)-\mathrm{C}\left(15^{*}\right)$ angle is rather acute at $93.3(3)^{\circ}$. If this contact is considered in the outer coordination sphere of $\mathrm{Hg}(1)$, the coordination geometry could be described as highly distorted trigonal bipyramid.

Compound $\mathbf{1}$ is a further example of the series of similar bimetallic complexes whose crystal structures were reported earlier (compounds $\mathrm{LHgCl}_{2} \cdot \mathrm{DMSO}, \mathrm{LHgCl}_{2} \cdot \mathrm{DMF}$ and $\mathrm{LCdCl}_{2} \cdot \mathrm{DMF}$ ) [8]. In these complexes, chloride ligands were present instead of thiocyanate and either dimethylformamide (DMF) or dimethylsulfoxide, the solvents used for crystallization, had become coordinated to atom $\mathrm{Hg}(1)$ (atom $\mathrm{Cd}(1)$ in $\mathrm{LCdCl}_{2} \cdot \mathrm{DMF}$ ), which was thus five-coordinate. In 1, despite being crystallized from DMF/ 


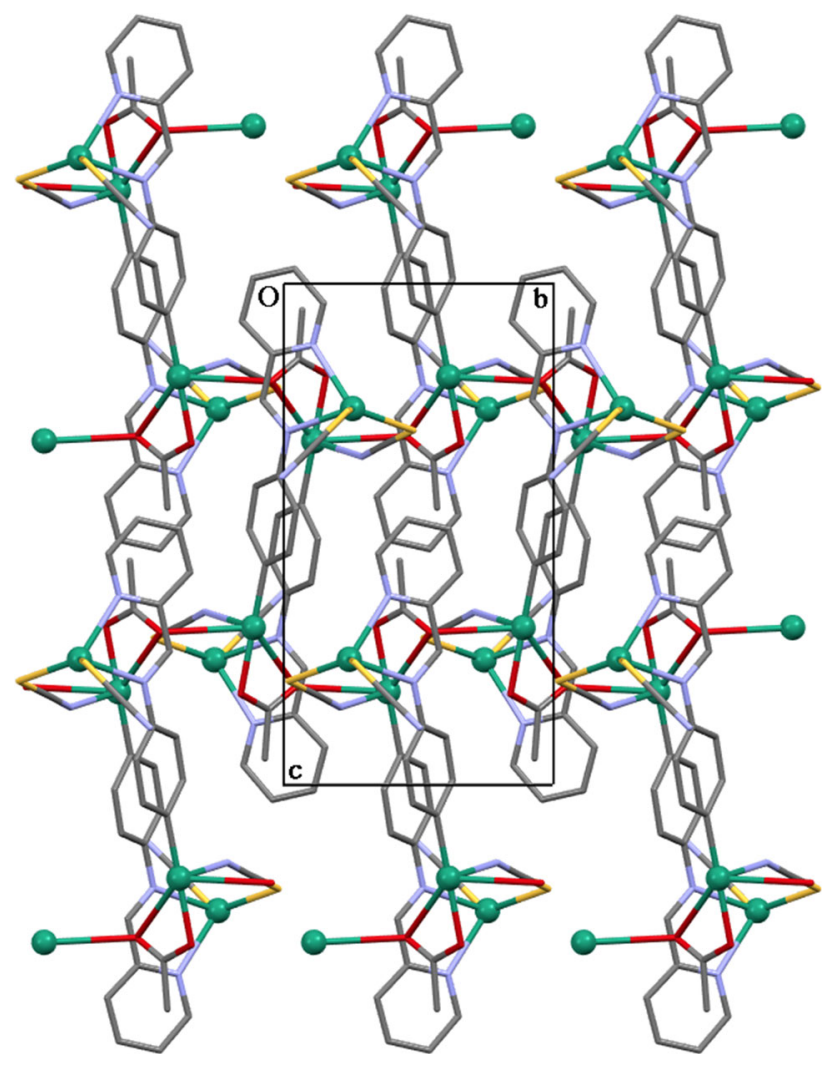

Fig. 2 One layer of the two-dimensional coordination polymer in the structure of $\mathbf{1}$, viewed down the $a$-axis. The $\mathrm{Hg}$ atoms are the cyancolored spheres and the $\mathrm{Hg} \cdots \mathrm{O}$ linkages between SBUs are clearly visible as the near-horizontal cyan-red bonds, some of which are terminating in this view (Color figure online) acetonitrile, DMF is not incorporated into the complex and $\mathrm{Hg}(1)$ is four-coordinate with a wide $\mathrm{S}-\mathrm{Hg}-\mathrm{S}$ angle accommodating the weak inter-sheet interactions described above. Atom $\mathrm{Hg}(2)$ in $\mathbf{1}$ is five-coordinate, including three weaker long interactions, whereas in $\mathrm{LHgCl}_{2} \cdot \mathrm{DMSO}$, $\mathrm{LHgCl}_{2} \cdot \mathrm{DMF}$ and $\mathrm{LCdCl}_{2} \cdot \mathrm{DMF}$, this atom is four-coordinate with two weak interactions to neighboring asymmetric units. Whereas 1 is a two-dimensional coordination polymer in which all linkages within the polymer involve only atom $\mathrm{Hg}(2), \mathrm{LHgCl}_{2} \cdot \mathrm{DMSO}, \mathrm{LHgCl}_{2} \cdot \mathrm{DMF}$ and $\mathrm{LCdCl}_{2}$. DMF are one-dimensional polymers in which the connections involve a route through both $\mathrm{Hg}$-atoms (the $\mathrm{Hg}$ and Cd-atoms in $\mathrm{LCdCl}_{2} \cdot \mathrm{DMF}$ ) [8]. One can speculate upon the cause of the different polymeric structure found for $\mathbf{1}$ and surmise that the steric bulk of the thiocyanate ligands, compared with the chloride ligands present in the other structures, might be a contributing factor.

There are two further notable differences between the structure of $\mathbf{1}$ and those of $\mathrm{LHgCl}_{2} \cdot \mathrm{DMSO}, \mathrm{LHgCl}_{2} \cdot \mathrm{DMF}$ and $\mathrm{LCdCl}_{2}$.DMF. In the $\mathrm{L}$ ligand of $\mathrm{LHgCl}_{2} \cdot \mathrm{DMSO}$, $\mathrm{LHgCl}_{2} \cdot \mathrm{DMF}$ and $\mathrm{LCdCl}_{2} \cdot \mathrm{DMF}$, the imine $\mathrm{Hg}-\mathrm{N}$ bonds were found to be consistently longer than the pyridine $\mathrm{Hg}-$ $\mathrm{N}$ bonds (Table 2), whereas the $\mathrm{Hg}-\mathrm{N}$ distances in $\mathbf{1}$ are equivalent. The imine ligand in $\mathbf{1}$ is twisted significantly from a planar conformation, with the dihedral angle between the planes of the phenyl and pyridyl rings being $37.6(2)^{\circ}$, compared with a more planar arrangement in the other structures, for example the corresponding dihedral angle in $\mathrm{LHgCl}_{2} \cdot \mathrm{DMF}$ is $11.5(3)^{\circ}$. The planes of the

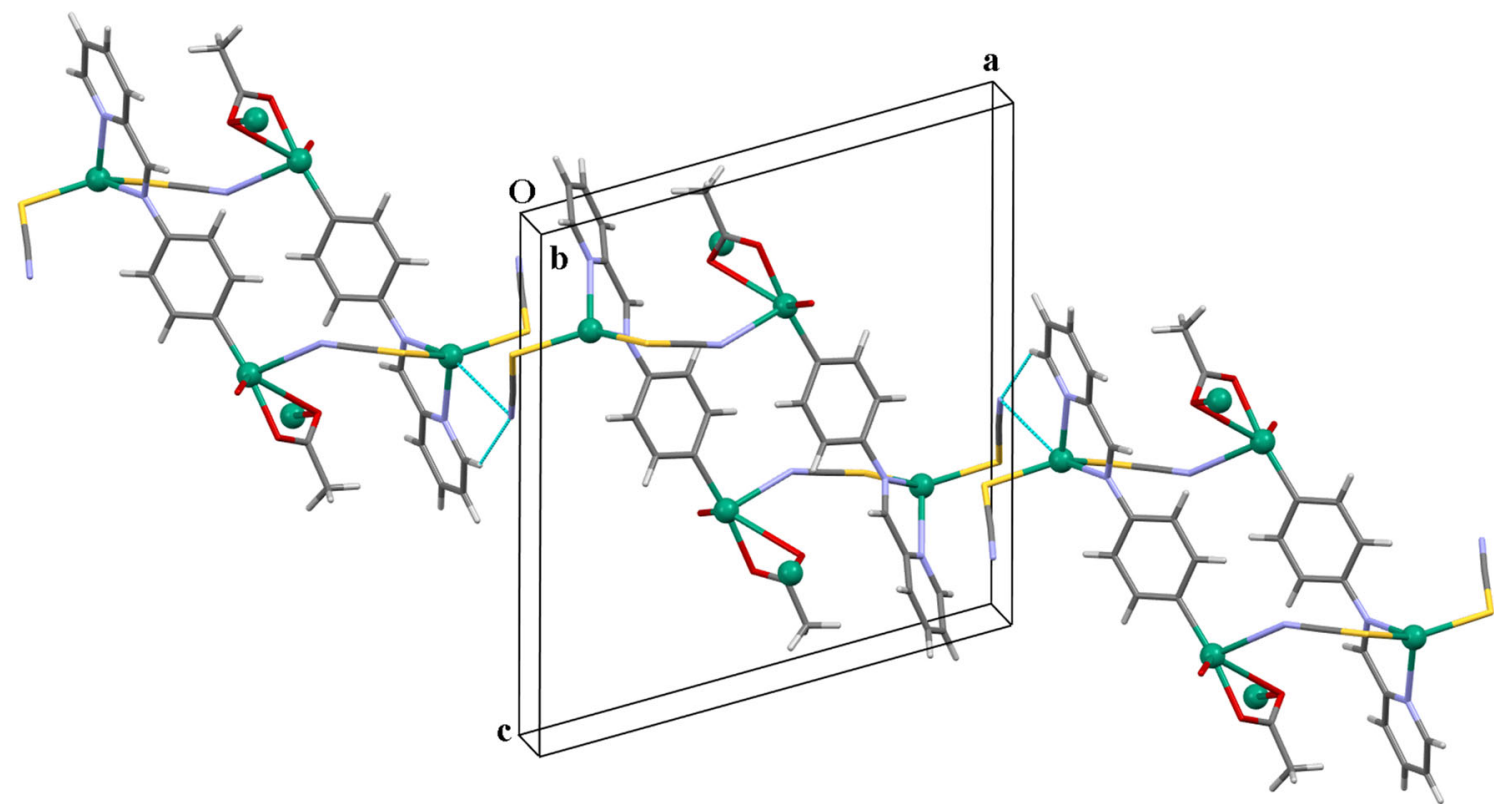

Fig. 3 The weak $\mathrm{Hg} \cdots \mathrm{N}$ and $\mathrm{C}-\mathrm{H} \cdots \mathrm{N}$ interactions (blue dashed lines) linking the tetranuclear SBUs of $\mathbf{1}$ to complete the three-dimensional supramolecular framework. The two-dimensional sheets resulting from the $\mathrm{Hg}(2) \cdots \mathrm{O}\left(2^{\prime \prime}\right)$ interaction lie parallel to the $b c$-plane and the linkages to the $\mathrm{Hg}(2)$ atom of the adjacent SBUs in the sheet are included. The $\mathrm{Hg}$ atoms are the cyan-colored spheres (Color figure online) 
chelating five-membered ring and the pyridine ring in $\mathbf{1}$ have a dihedral angle of $6.8(3)^{\circ}$, similar to the values found in the other structures.

\section{Supplementary Materials}

CCDC-1035223 contains the supplementary crystallographic data for this paper. These data can be obtained free of charge from The Cambridge Crystallographic Data Centre via www.ccdc.cam.ac.uk/data_request/cif.

Acknowledgments The financial support of the University Grants Commission, New Delhi, India through SAP-CAS, Phase-I and the Indo-Swiss Joint Research Programme, Joint Utilisation of Advanced Facilities (Grant Nos. JUAF 11, TSBB, AL) are gratefully acknowledged.

\section{References}

1. Vernet P (1991) Heavy metals in the environment. Elsevier Science, New York
2. Borsari M (1994) In: King RB (ed) Encyclopedia of inorganic chemistry. Wiley, New York

3. Mahmoudi G, Morsali A (2007) Cryst Eng Commun 9:1062-1072

4. Morsali A, Masoomi MY (2009) Coord Chem Rev 253:1882-1905

5. Basu Baul TS, Kundu S, Mitra S, Höpfl H, Tiekink ERT, Linden A (2013) Dalton Trans 42:1905-1920

6. Basu Baul TS, Kundu S, Höpfl H, Tiekink ERT, Linden A (2013) Polyhedron 55:270-282

7. Basu Baul TS, Kundu S, Höpfl H, Tiekink ERT, Linden A (2014) J Coord Chem 67:1061-1078

8. Basu Baul TS, Longkumer I, Linden A (2014) J Organomet Chem 761:156-168

9. Bloodworth AJ (1970) J Organomet Chem 23:27-30

10. CrysAlisPro (2012) Version 1.171.36.20. Agilent Technologies, Yarnton

11. Coppens P, Leiserowitz L, Rabinovich D (1965) Acta Crystallogr 18:1035-1038

12. Sheldrick GM (2008) SHELXS97. Acta Crystallogr A 64:112-122

13. Sheldrick GM (2015) SHELXL2013. Acta Crystallogr C 71:3-8

14. Nakamoto K (2009) Infrared and Raman spectra of inorganic and coordination compounds, part B, 5th edn. Wiley, New Jersey

15. Daković M, Popović Z, Giester G, Rajić-Linarić M (2008) Polyhedron 27:210-222 